\title{
Perceptions of Athletic Trainers as a Source of Nutritional Information among Collegiate Athletes: A Mixed-methods Approach
}

\author{
Rebecca A. Schlaff (Corresponding author) \\ Department of Kinesiology, Saginaw Valley State University, 7400 Bay Road, University Center, MI 48710, USA \\ E-mail: raschlaf@svsu.edu \\ Valerie J. Adams \\ Duke University School of Medicine, Durham, NC 27708, USA \\ E-mail: valerie.adams@duke.edu \\ Daniel J. Crusoe \\ University of Michigan-Flint, 303 E. Kearsley St., Flint, MI 48502, USA \\ E-mail: djcrusoe0929@gmail.com \\ Jeremy L. Knous \\ Department of Kinesiology, Saginaw Valley State University, 7400 Bay Road, University Center, MI 48710, USA \\ E-mail: jknous@svsu.edu \\ Meghan Baruth \\ Department of Health Science, Saginaw Valley State University, 7400 Bay Road, University Center, MI 48710, USA \\ E-mail: mbaruth@svsu.edu
}

Received: 18-02-2016

doi:10.7575/aiac.ijkss.v.4n.2p.55
Accepted: 16-04-2016

Published: 30-04-2016

\begin{abstract}
Background: Athletes obtain nutrition information from a number of sources, with some being more accurate than others. Little is known about athletes' perceptions of utilizing Certified Athletic Trainers (ATs) as a primary source of information. Objective: We sought to 1) examine the primary sources of nutrition information among a group of United States collegiate athletes and 2) understand athletes' perceptions regarding utilization of their ATs as primary sources of nutrition information. Methods: Participants (Division II university athletes) completed an online questionnaire $(\mathrm{n}=155 ; \mathrm{n}=58$ males, $\mathrm{n}=97$ females) assessing demographic information and ranked primary sources of nutrition information, and participated in focus groups $(n=26 ; n=18$ women, $n=8$ men) to better understand barriers/perceptions for using their ATs for nutrition information. Mean+SD ranking were calculated for all sources. Mann Whitney-U analyses were used to identify differences in rank order nutrition sources between genders and years of collegiate experience. Semi-structured focus groups were transcribed, coded, and themes were identified regarding barriers to utilizing ATs for nutrition-related information. Results: Parents (3.54 \pm 2.38$)$ and the internet (3.69 \pm 2.29$)$ had the highest mean ranks. ATs were least often ranked as the number one nutrition source (7.5\%), among all sources provided. Barriers to utilizing ATs for nutritional information included discomfort, nutrition information not being within the scope of practice, lack of knowledge, the athletic trainer not caring, and lack of time. Conclusions: Participants reported utilizing ATs less than previous research indicates. Continuing education may be needed to improve the efficacy of ATs in addressing nutritional issues and being seen as a credible and accessible source.
\end{abstract}

Keywords: Diet, Athlete perceptions, Barriers

\section{Introduction}

Athletic Trainers are recognized as a member of the allied health care profession, whose primary practice "encompasses the prevention, examination, diagnosis, treatment and rehabilitation of emergent, acute and chronic injuries and medical condition."("National Athletic Trainers' Association: Athletic Training," 2015) Within the field of Athletic Training, it is recognized that the education of prospective Athletic Trainers (ATs) must focus in part on mastering competencies related to nutrition, because of its direct relationship with overall health and performance. As such, the Board of Certification (BOC) Role Delineation/Practice Analysis (6th Edition)(Board of Certification for the Athletic Trainer: Role Delineation Study/Practice Analysis, 6th edition, 2011) depicts the current knowledge and skills entry-level ATs should possess within five domains and 28 tasks. Specifically related to nutrition, it states that all certified athletic trainers (ATs) should possess knowledge and skill in the following areas: general nutrition concepts, weight 
management and body composition, disordered eating and eating disorders, performance enhancing and recreational supplements and drugs, and prevention and health promotion. Unfortunately, previous research has indicated that, in general, ATs do not feel adequately equipped and confident in their ability to effectively handle the gamut of nutritional issues they are presented with as a practitioner,(Bonci et al., 2008; Thompson, Yingling, Boardley, \& Rocks, 2007; Whitson, Cordova, Demchak, Stemmans, \& King, 2006) potentially affecting athletes' health and injury risk.

Studies suggesting that ATs may lack appropriate confidence and comfort related to various nutritional issues are discouraging since data from previous research indicate that athletes tend to report utilizing ATs as a primary source of advice for various topics related to nutrition.(Burns, Schiller, Merrick, \& Wolf, 2004; B. H. Jacobson, Gemmel, H.A., 1991; B. H. Jacobson, Sobonya, \& Ransone, 2001) Specifically, previous studies have reported that ATs consistently rank within the top four sources of nutritional information, especially among collegiate athletes.(B. H. Jacobson, Gemmel, H.A., 1991; B. H. Jacobson et al., 2001) Among U.S. college athletes, health issues related to disordered eating and supplement use are matters that are all too commonly faced and well documented, with estimates of disordered eating ranging from 33-62\% in males and females(Bonci et al., 2008) and supplement use being reported in as many as $88 \%$ of athletes.(Burns et al., 2004) Consequently, since ATs appear to be a primary source of nutrition advice, it is important that they are educated, efficacious, and aware of the important role they play as a part of the multi-disciplinary sports medicine team.

Although some data are available to comment on the confidence level of ATs in handling issues related to nutrition, less is known about why athletes choose to utilize various sources of information. Specifically, little is known about athletes' perception, ease, and confidence in utilizing their ATs as a primary source of nutrition advice. Therefore, the purposes of this exploratory study were to 1) examine the primary sources of nutrition information among a group of Division II varsity collegiate athletes, with specific interest in the impact of athlete characteristics (gender and years of experience), and where ATs rank (via survey) and 2) understand athletes' perceptions regarding utilization of their ATs as primary sources of nutrition information via participation in a focus group (a qualitative approach).

\section{Methods}

The data used in this study was a part of a project aimed at understanding the nutrition knowledge, practices, and resources of student-athletes.(Adams, Goldufsky, \& Schlaff, 2016) The overarching goal of this project was to develop a program for college student-athletes that improved access to quality nutritional knowledge and to improve athletic and academic performance through improved nutritional practices. As a part of the overall study, data regarding the perception, ease, and confidence in utilizing ATs as a primary source of nutrition advice was collected from U.S. National Collegiate Athletic Association (NCAA) college student-athletes and is the basis for this study.

\subsection{Participants}

Student athletes from a Midwestern, NCAA Division II University in the United States were invited to take part in this study ( $n=465$ student athletes from 17 varsity sports). A total of 155 student athletes $(n=58$ males and $n=97$ females) completed the survey and were included in the quantitative portion of this study. Of the 155 participants completing the survey, 26 student-athletes ( $n=18$ women and $n=8$ men from 12 varsity sports) participated in a focus group ( $n=2)$ and were included in the qualitative portion of this study.

\subsection{Instrumentation}

The questionnaire utilized in this study was modified from previously validated surveys.(Garner \& Garfinkel, 1979 ; B. H. Jacobson et al., 2001; McNulty, Adams, Anderson, \& Affenito, 2001) Participants self-reported their gender, varsity sport, the number of years competing at the collegiate level, and their height and weight (used to calculated body mass index, $\mathrm{kg} / \mathrm{m}^{2}$ ). Sources of nutritional information were assessed by asking participants where they most frequently sought nutritional advice. Participants ranked the following from 1 (most frequent) to 8 (least frequent), when applicable: AT, coach, magazine, strength \& conditioning coach, college course, teammates, and parents.

Each focus group followed a semi-structured format in which open-ended questions were used to stimulate discussion on topics related to nutritional sources, knowledge, and needs. The questions included: What sources do you most commonly utilize for nutritional advice and information?; why do you seek advice from the sources you indicated?; tell us about your confidence level in the accuracy of the sources you utilize; how do you feel about utilizing your ATs as a source of nutrition information?; what barriers exist to talking to your ATs about nutrition?

\subsection{Procedures}

A list of all varsity athletes' email addresses was obtained from an athletic department administrator. An email with the link to the survey was sent to all athletes inviting participation in nutrition-related survey. All participants in this study completed an informed consent form approved by the University's Institutional Review Board.

In an effort to better understand why athletes utilized various nutritional sources and their perception of utilizing ATs as a source of nutritional knowledge, participants completing the survey were invited to take part in a focus group aimed at gaining a better understanding of nutritional needs. Participants indicating interest were sent a follow-up email with additional details; all interested student-athletes were able to participate. The qualitative data collected would complement the quantitative data, validate these findings, and perhaps provide a more in depth understanding of the results from the survey. A focus group guide, along with probes, focused on eliciting responses regarding why athletes utilized various nutritional sources and their perception of utilizing ATs as a source of nutritional knowledge, was 
developed for this study. A total of two focus groups were conducted by a faculty member and a trained undergraduate student, and audio recordings from both were transcribed verbatim. Although the focus group included questions and discussions relevant to the overall, larger study goal, discussion surrounding nutrition information sources, specifically with regard to the AT staff, were used in this study.

\subsection{Statistical Analyses}

Questionnaire data were utilized to calculate descriptive statistics (means and frequencies) for demographic-related data and sources of nutrition information. To explore whether descriptive characteristics affected utilization of nutrition sources, athletes were dichotomized in two ways: years of collegiate experience $(<2$ years competing at the collegiate level and $>2$ years competing at the collegiate level) and gender. Mann Whitney- $U$ analyses were used to identify differences in rank order of athletes' primary nutrition sources with respect to gender and years of collegiate athletic participation. An alpha level of 0.05 was used to determine significance. All analyses were conducted using SPSS.

Three researchers independently reviewed the transcripts from the focus groups and developed a coding guide. After in-depth discussion and agreement on the coding guide, three researchers independently coded each of the transcripts. Next, in a group meeting, the researchers compared the codes, discussed areas of agreement and disagreement, and reached consensus. The coded data were placed into common themes, agreed upon by the researchers. Content related to barriers to utilizing ATs for nutrition-related information was the basis for this report. Dominant themes appeared multiple times within and across focus group transcripts. Dominant themes, along with illustrative quotations, are presented.

\section{Results}

\subsection{Survey}

A total of 155 student athletes completed the survey (33\% response rate). Demographic characteristics of the participants are shown in Table 1.

Table 1. Demographic Characteristics of Participants $(\mathrm{n}=155)$

\begin{tabular}{|c|c|c|c|c|}
\hline & \multicolumn{2}{|c|}{ Males $(n=58)$} & \multicolumn{2}{|c|}{ Females $(n=97)$} \\
\hline & $\mathrm{N}$ & Mean (SD) or $\%$ & $\mathrm{~N}$ & Mean (SD) or $\%$ \\
\hline \multicolumn{5}{|l|}{ Sport } \\
\hline Baseball & 17 & 29.3 & N/A & N/A \\
\hline Softball & N/A & N/A & 18 & 18.5 \\
\hline Basketball & 1 & 1.7 & 13 & 13.4 \\
\hline Cross country/track & 6 & 10.3 & 15 & 15.4 \\
\hline Football & 13 & 22.4 & $\mathrm{~N} / \mathrm{A}$ & N/A \\
\hline Golf & 3 & 5.1 & N/A & N/A \\
\hline Soccer & 13 & 22.4 & 13 & 13.4 \\
\hline Track and Field & 5 & 8.6 & 13 & 13.4 \\
\hline Volleyball & $\mathrm{N} / \mathrm{A}$ & N/A & 10 & 10.3 \\
\hline Cheerleading & N/A & N/A & 11 & 11.3 \\
\hline Tennis & $\mathrm{N} / \mathrm{A}$ & N/A & 4 & 4.1 \\
\hline Years competing at collegiate level & 58 & $2.0(1.3)$ & 97 & $2.1(1.2)$ \\
\hline Body mass index, $\mathrm{kg} / \mathrm{m}^{2}$ & 57 & $25.3(4.0)$ & 91 & $24.9(3.3)$ \\
\hline Height $(\mathrm{cm})$ & & $182.5(7.1)$ & & $160.3(8.8)$ \\
\hline Weight $(\mathrm{kg})$ & & $84.3(16.9)$ & & $64.0(13.6)$ \\
\hline
\end{tabular}

The mean rank for each source of nutrition-related information for the entire group, by gender, and by years of competition is presented in Table 2 .

Table 2. Differences in Mean Ranking of Sources of Nutrition-related Information according to Gender and Years of Competition

\begin{tabular}{|c|c|c|c|c|c|c|c|c|c|c|c|c|}
\hline \multirow[b]{2}{*}{ Source } & \multirow{2}{*}{\multicolumn{2}{|c|}{$\begin{array}{c}\text { All Athletes } \\
\text { Entire Sample } \\
(\mathrm{n}=155)\end{array}$}} & \multicolumn{5}{|c|}{ Gender } & \multicolumn{5}{|c|}{ Years of Competition } \\
\hline & & & \multicolumn{2}{|c|}{$\begin{array}{l}\text { Males } \\
(\mathrm{n}=58)\end{array}$} & \multicolumn{2}{|c|}{$\begin{array}{c}\text { Females } \\
(n=97)\end{array}$} & \multirow[t]{2}{*}{$\begin{array}{c}\mathrm{p}- \\
\text { value }\end{array}$} & \multicolumn{2}{|c|}{$\begin{array}{l}\text { Older } \\
\text { athletes } \\
(\mathrm{n}=72)\end{array}$} & \multicolumn{2}{|c|}{$\begin{array}{l}\text { Younger } \\
\text { athletes } \\
(n=83)\end{array}$} & \multirow[t]{2}{*}{$\begin{array}{c}\mathrm{p}- \\
\text { value }\end{array}$} \\
\hline & $\mathrm{N}$ & $\begin{array}{l}\text { Mean } \\
(\mathrm{SD})\end{array}$ & $\mathrm{N}$ & $\begin{array}{l}\text { Mean } \\
(\mathrm{SD})\end{array}$ & $\mathrm{N}$ & $\begin{array}{c}\text { Mean } \\
(\mathrm{SD})\end{array}$ & & $\mathrm{N}$ & $\begin{array}{l}\text { Mean } \\
(\mathrm{SD})\end{array}$ & $\mathrm{N}$ & $\begin{array}{c}\text { Mean } \\
(\mathrm{SD})\end{array}$ & \\
\hline Coach & 118 & $\begin{array}{c}4.28 \\
(2.45)\end{array}$ & 43 & $\begin{array}{c}4.70 \\
(2.58)\end{array}$ & 75 & $\begin{array}{c}4.04 \\
(2.35)\end{array}$ & 0.16 & 60 & $\begin{array}{c}4.45 \\
(2.70)\end{array}$ & 58 & $\begin{array}{c}4.10 \\
(2.17)\end{array}$ & 0.47 \\
\hline
\end{tabular}




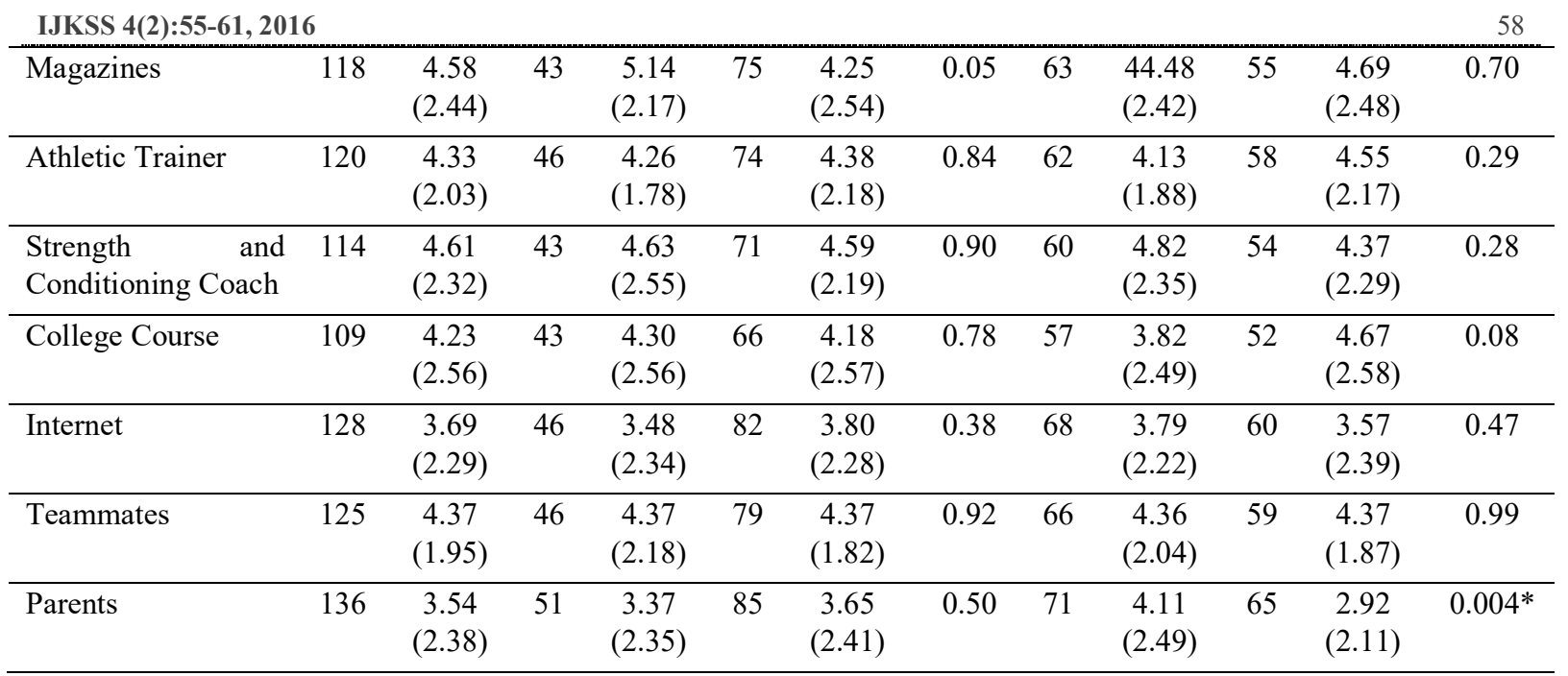

* indicates statistically significant difference $(\mathrm{p}<0.05)$; Athletes with fewer years of experience competing at the college level were more likely to report utilizing their parents and primary sources of nutrition information.

The percentage of athletes ranking each source of information (from 1-8) among those who reported receiving nutritionrelated information from each source is shown in Table 3. Strength and conditioning coach (9.6\%) and ATs (7.5\%) were the sources least often ranked as number one.

Table 3. Percentage of Participants Ranking Each Source of Nutrition Information

\begin{tabular}{|c|c|c|c|c|c|c|c|c|c|}
\hline \multirow[b]{3}{*}{ Source } & \multicolumn{9}{|c|}{ Entire Sample, All Athletes, \% (n) } \\
\hline & \multicolumn{9}{|c|}{ Nutrition ranking (1-8) } \\
\hline & $\mathrm{N}$ & 1 & 2 & 3 & 4 & 5 & 6 & 7 & 8 \\
\hline Coach & 118 & $\begin{array}{l}21.2 \\
(25)\end{array}$ & $\begin{array}{c}8.5 \\
(10)\end{array}$ & $\begin{array}{l}11.0 \\
(13)\end{array}$ & $\begin{array}{l}12.7 \\
(15)\end{array}$ & $\begin{array}{l}10.2 \\
(12)\end{array}$ & $\begin{array}{l}13.6 \\
(16)\end{array}$ & $\begin{array}{c}9.3 \\
(11)\end{array}$ & $\begin{array}{l}13.6 \\
(16)\end{array}$ \\
\hline Magazines & 118 & $\begin{array}{l}11.0 \\
(13)\end{array}$ & $\begin{array}{l}16.9 \\
(20)\end{array}$ & $\begin{array}{l}11.9 \\
(14)\end{array}$ & $\begin{array}{l}10.2 \\
(12)\end{array}$ & $\begin{array}{l}11.9 \\
(14)\end{array}$ & $\begin{array}{c}8.5 \\
(10)\end{array}$ & $\begin{array}{l}11.0 \\
(13)\end{array}$ & $\begin{array}{l}18.6 \\
(22)\end{array}$ \\
\hline Athletic Trainer & 120 & $\begin{array}{l}7.5 \\
(9)\end{array}$ & $\begin{array}{l}15.0 \\
(18)\end{array}$ & $\begin{array}{l}14.2 \\
(17)\end{array}$ & $\begin{array}{l}20.8 \\
(25)\end{array}$ & $\begin{array}{c}9.2 \\
(11)\end{array}$ & $\begin{array}{l}15.8 \\
(19)\end{array}$ & $\begin{array}{l}10.8 \\
(13)\end{array}$ & $\begin{array}{l}6.7 \\
(8)\end{array}$ \\
\hline $\begin{array}{l}\text { Strength and } \\
\text { Conditioning } \\
\text { Coach }\end{array}$ & 114 & $\begin{array}{l}9.6 \\
(11)\end{array}$ & $\begin{array}{l}17.5 \\
(20)\end{array}$ & $\begin{array}{l}9.6 \\
(11)\end{array}$ & $\begin{array}{l}9.6 \\
(11)\end{array}$ & $\begin{array}{l}15.8 \\
(18)\end{array}$ & $\begin{array}{l}6.1 \\
(7)\end{array}$ & $\begin{array}{l}20.2 \\
(23)\end{array}$ & $\begin{array}{l}11.4 \\
(13)\end{array}$ \\
\hline College Course & 109 & $\begin{array}{l}21.1 \\
(23)\end{array}$ & $\begin{array}{l}14.7 \\
(16)\end{array}$ & $\begin{array}{l}8.3 \\
(9)\end{array}$ & $\begin{array}{l}10.1 \\
(11)\end{array}$ & $\begin{array}{l}8.3 \\
(9)\end{array}$ & $\begin{array}{l}14.7 \\
(16)\end{array}$ & $\begin{array}{l}5.5 \\
(6)\end{array}$ & $\begin{array}{l}17.4 \\
(19)\end{array}$ \\
\hline Internet & 128 & $\begin{array}{l}23.4 \\
(30)\end{array}$ & $\begin{array}{l}15.6 \\
(20)\end{array}$ & $\begin{array}{l}14.8 \\
(19)\end{array}$ & $\begin{array}{l}10.2 \\
(13)\end{array}$ & $\begin{array}{l}9.4 \\
(12)\end{array}$ & $\begin{array}{l}11.7 \\
(15)\end{array}$ & $\begin{array}{l}7.0 \\
(9)\end{array}$ & $\begin{array}{c}7.8 \\
(10)\end{array}$ \\
\hline Teammates & 125 & $\begin{array}{l}10.4 \\
(13)\end{array}$ & $\begin{array}{l}10.4 \\
(13)\end{array}$ & $\begin{array}{l}10.4 \\
(13)\end{array}$ & $\begin{array}{l}18.4 \\
(23)\end{array}$ & $\begin{array}{l}22.4 \\
(28)\end{array}$ & $\begin{array}{l}11.2 \\
(14)\end{array}$ & $\begin{array}{l}12.8 \\
(16)\end{array}$ & $\begin{array}{r}4.0 \\
(5)\end{array}$ \\
\hline Parents & 136 & $\begin{array}{l}29.4 \\
(40)\end{array}$ & $\begin{array}{l}13.2 \\
(18)\end{array}$ & $\begin{array}{l}15.4 \\
(21)\end{array}$ & $\begin{array}{l}8.1 \\
(11)\end{array}$ & $\begin{array}{c}7.4 \\
(10)\end{array}$ & $\begin{array}{l}10.3 \\
(14)\end{array}$ & $\begin{array}{c}8.1 \\
(11)\end{array}$ & $\begin{array}{l}8.1 \\
(11)\end{array}$ \\
\hline
\end{tabular}

\subsection{Focus Groups}

A total of 26 student-athletes took part in the focus groups (18 women, 7 men, with representation from 12 of 17 varsity sports). A number of themes regarding barriers to using ATs as a source of nutritional information emerged. The most commonly cited theme was feeling uncomfortable. Athletes cited being a pest or bother, an inconvenience, and lack of privacy as reasons for feeling uncomfortable. Other dominant themes included the provision of nutrition information not being within the scope of an AT's practice, lack of knowledge, the athletic trainer not caring, and lack of time. Dominant themes and illustrated quotes are found in Table 4. 
Table 4. Barriers to Using ATs at Nutritional Sources: Themes and Select Illustrative Quotes

\begin{tabular}{ll}
\hline Theme & Example quotes \\
\hline Feeling uncomfortable & "I'm not comfortable asking any question because you \\
think, oh someone might think that's a dumb question."
\end{tabular}

"I'd feel uncomfortable going to talk to them about nutrition. I don't know that they have a private way to do it."

Not within scope of AT practice

".........Like they are there to tape ankles, take you to the ER [emergency room] if something really serious happens."

Lack of AT knowledge

"I think they have just a general knowledge of nutrition.

I know everyone is different and nutritional needs vary from sport to sport and from individual to individual and I don't think they can give you a straight answer for that specifically because their knowledge is just overall in general, like all of ours."

AT not caring "I feel like they don't care honestly about
nutrition........"

Lack of AT time

"...the athletic trainers are busy, and there are not a lot of them. So, if you do read something on the Internet, if you do hear something from a teammate, there's really not a source to go talk to actually have it confirmed."

\section{Discussion}

It has been well established that optimal nutrition is important for enhancing both athletic performance and recovery.(American Dietetic et al., 2009) However, available data indicate that collegiate athletes tend to lack adequate knowledge related to the basic principles of nutrition and fueling their bodies for optimal performance and recovery.(Dunn D., 2007; B. H. Jacobson, Gemmel, H.A., 1991; B. H. Jacobson et al., 2001; Torres-McGehee et al., 2012; Zawila, Steib, \& Hoogenboom, 2003) Therefore, it is important that collegiate athletes have easily accessible resources for nutrition education and guidance. Some of the most proximate sources for these athletes often include their coaches, strength and conditioning coaches, and ATs. Although these sources of information hold the potential to be both accessible and accurate, previous research indicates that athletes tend to report utilizing sources such as the internet, magazines, and parents(B. H. Jacobson, Gemmel, H.A., 1991; B. H. Jacobson et al., 2001; Shifflett, Timm, \& Kahanov, 2002; Smith-Rockwell, 2001) more frequently, suggesting that barriers exist to utilizing members of the athletic staff (i.e. ATs, coaches and strength and conditioning coaches).

While we did not investigate nutrition knowledge of the athletes within our sample, our findings related to sources of nutrition information corroborated those of aforementioned studies, as internet and parents had the highest mean rank (i.e. athletes preferred to utilize these sources prior to other sources and most frequently; Table 2). A novel aspect of this investigation included the examination of whether differences in the rank order of nutritional information sources varied by demographic characteristics (specifically, gender and years of competition). Aside from younger athletes $(<2$ years of experience) ranking their parents as primary sources more frequently, no significant differences existed.

Furthermore, our data suggest that although athletes within our sample appeared to be in regular contact with their ATs, they were least frequently viewed as their primary (rank number one) source of nutritional information (Table 3). Previous research has not provided clear explanations for this under-utilization of ATs for nutritional information. While some evidence indicates that ATs have an adequate level of nutrition knowledge,(Shifflett et al., 2002; SmithRockwell, 2001; Torres-McGehee et al., 2012) other data suggest they feel inadequately prepared and equipped to counsel athletes about nutritional issues and identify athletes with disordered eating behaviors for referral.(Bonci et al., 2008; Thompson et al., 2007; Whitson et al., 2006). The interaction between 1) nutrition knowledge and perceived competence of ATs and 2) athletes' perception of their ATs' nutrition knowledge and competence may be an important predictor of whether college athletes choose to utilize these important members of their health care team for nutrition information. Previous research on the latter construct (athlete perception) is very limited. Therefore, it is crucial to understand athletes' perceptions of their ATs in this role; hence the qualitative (focus group) component of this investigation.

To our knowledge, we are among the first to qualitatively explore athletes' perceptions regarding the utilization of ATs for nutritional advice. Our findings suggest that, although the ATs accessible to the athletes within our sample may be educated about nutritional issues, there were many barriers present that prevented athletes from frequently approaching ATs for advice. Quantitative data obtained via questionnaire indicated that gender and years of experience did not differentially affect the likelihood of an athlete viewing their ATs as a primary source of information. The most meaningful insight into barriers was obtained from our qualitative focus group data. Interestingly, the "not within scope of practice" and "lack of knowledge" barriers contradict the findings of previous research highlighting ATs adequate 
level of knowledge,(Shifflett et al., 2002; Smith-Rockwell, 2001; Torres-McGehee et al., 2012) and are troubling since ATs may be the most accurate and accessible source for nutritional information athletes have. Conversely, the most frequently cited barrier athletes reported within our focus groups was feeling uncomfortable asking questions about nutrition, which mirrors the discomfort that has been previously reported within samples of ATs in dealing with some nutritional issues.(Bonci et al., 2008; Thompson et al., 2007; Whitson et al., 2006) It is possible that, although inadvertently, the discomfort experienced by an AT with addressing some nutritional issues is perceived by the athletes within their care, resulting in athlete discomfort and a perception that their AT does not have time to talk with them and does not care about their nutritional status. Unfortunately, we were unable to locate any previous reports commenting on whether ATs identify with any of the other barriers the athletes within our sample reported.

\section{Conclusion}

Moving forward, it is crucial that ATs are cognizant of the important role they play in the deliverance of nutritional information, as they are often working in close contact with collegiate athletes on a regular basis, and are sensitive to the barriers ascertained within the present study, particularly since the knowledge level of ATs has been shown to be better than other members of the athletic staff (i.e. coaches and strength and conditioning coaches)(Torres-McGehee et al., 2012). Furthermore, our findings suggest that additional work is necessary to ensure athletes are aware that nutrition education is within their AT's scope of practice. This is especially important at universities that do not have financial means to employ a Registered Dietitian as a part of the athletes' integrated health care team (such as the university in which the sample was obtained).

The novelty of this investigation warrants future research with improved methodologies. Given our relatively small, convenience sample and investigation within a singular Division II institution, future research with larger sample sizes should both quantitatively and qualitatively examine nutrition information sources and barriers to effective communication between collegiate athletes and their ATs among NCAA Division I, II, and III institutions to better understand why athletes choose to utilize various sources of nutrition information and to improve upon the relationship between ATs and the athletes under their care.

\section{References}

Adams, V. J., Goldufsky, T. M., \& Schlaff, R. A. (2016). Perceptions of body weight and nutritional practices among male and female National Collegiate Athletic Association Division II athletes. Journal of American College Health, 64(1), 19-24. doi:10.1080/07448481.2015.1062770

American Dietetic, A., Dietitians of, C., American College of Sports, M., Rodriguez, N. R., Di Marco, N. M., \& Langley, S. (2009). American College of Sports Medicine position stand. Nutrition and athletic performance. Medicine and Science in Sports and Exercise, 41(3), 709-731. doi:10.1249/MSS.0b013e31890eb86

Board of Certification. (2010). The 2009 Athletic Trainer Role Delineation Study. Omaha, NE: Stephen B. Johnson.

Bonci, C. M., Bonci, L. J., Granger, L. R., Johnson, C. L., Malina, R. M., Milne, L. W., . . Vanderbunt, E. M. (2008). National athletic trainers' association position statement: preventing, detecting, and managing disordered eating in athletes. Journal of Athletic Training, 43(1), 80-108. doi:10.4085/1062-6050-43.1.80

Burns, R. D., Schiller, M. R., Merrick, M. A., \& Wolf, K. N. (2004). Intercollegiate student athlete use of nutritional supplements and the role of athletic trainers and dietitians in nutrition counseling. Journal of the American Dietetic Association, 104(2), 246-249. doi:10.1016/j.jada.2003.11.013

Dunn D., T., L.W., Denny G. (2007). Nutrition knowledge and attitudes of college athletes. The Sport Journal, 10(4), 15 .

Garner, D. M., \& Garfinkel, P. E. (1979). The Eating Attitudes Test: an index of the symptoms of anorexia nervosa. Psychological Medicine, 9(2), 273-279.

Jacobson, B. H., Gemmel, H.A. (1991). Nutrition Information Sources of College Varsity Athletes. Journal of Applied Sport Science Research, 5(4). 204-207.

Jacobson, B. H., Sobonya, C., \& Ransone, J. (2001). Nutrition practices and knowledge of college varsity athletes: a follow-up. Journal of Strength and Conditioning Research, 15(1), 63-68.

McNulty, K. Y., Adams, C. H., Anderson, J. M., \& Affenito, S. G. (2001). Development and validation of a screening tool to identify eating disorders in female athletes. Journal of the American Dietetic Association, 101(8), 886-892; quiz 893-884. doi:10.1016/S0002-8223(01)00218-8

National Athletic Trainers' Association: Athletic Training. (2015). Retrieved from https://http://www.nata.org/about/athletic-training.

Shifflett, B., Timm, C., \& Kahanov, L. (2002). Understanding of athletes' nutritional needs among athletes, coaches, and athletic trainers. Research Quarterly for Exercise and Sport, 73(3), 357-362. doi:10.1080/02701367.2002.10609032

Smith-Rockwell, M., Nickols-Richardson, S.M., Thye, F.W. (2001). Nutrition Knowledge, Opinions, and Practices of Coaches and Athletic Trainers at a Division I University. International Journal of Sport Nutrition and Exercise Metabolism, 11, 174-185. 
Thompson, A., Yingling, F., Boardley, D., \& Rocks, J. (2007). Collegiate athletic trainers' knowledge and perceptions of disordered eating behaviors in athletes. Psychol Rep, 101(3 Pt 2), 1173-1178. doi:10.2466/pr0.101.4.1173-1178

Torres-McGehee, T. M., Pritchett, K. L., Zippel, D., Minton, D. M., Cellamare, A., \& Sibilia, M. (2012). Sports nutrition knowledge among collegiate athletes, coaches, athletic trainers, and strength and conditioning specialists. Journal of Athletic Training, 47(2), 205-211.

Whitson, E., Cordova, M. L., Demchak, T., Stemmans, C. L., \& King, K. A. (2006). Certified athletic trainers' knowledge and perception of professional preparation involving eating disorders among athletes. J Allied Health, 35(1), 18-29.

Zawila, L. G., Steib, C. S., \& Hoogenboom, B. (2003). The Female Collegiate Cross-Country Runner: Nutritional Knowledge and Attitudes. Journal of Athletic Training, 38(1), 67-74. 